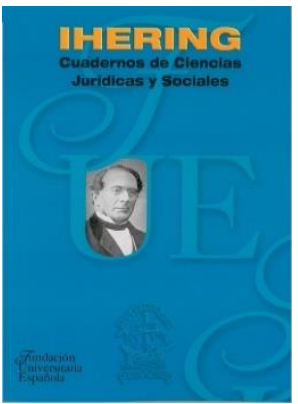

(c) $($ ) (9)
Ihering. Cuadernos de Ciencias Jurídicas y Sociales N. 04

Año: 2021

Publicación del SEMINARIO DE ESTUDIOS EUROPEOS "DIEGO DE MENDOZA" de la

Fundación Universitaria Española

e-ISSN: 2660-552X

DOI: https://doi.org/10.51743/ihering.275

Recibido: 29-11-2021 | Revisado: 20-12-2021

|Aceptado: 22-12-2021 | Publicado: 23-12-2021

\title{
LA UNIÓN FRANCO-BRITÁNICA DE 1940: UNA DECISIÓN QUE PUDO CAMBIAR LA HISTORIA DE EUROPA EN EL SIGLO XX
}

THE FRANCO-BRITISH UNION OF 1940: A DECISION THAT COULD CHANGE THE HISTORY OF EUROPE IN THE 20TH CENTURY

\author{
MANUEL ARAZOLA MARTÍNEZ \\ Universidad Rey Juan Carlos
}

\section{Resumen}

En el comienzo de la Segunda Guerra Mundial, cuando estaba a punto de capitular la República francesa tras la ofensiva alemana de la primavera de 1940, los gobiernos aliados de Gran Bretaña y Francia debatieron un proyecto para la creación de un nuevo Estado: la Unión Franco-Británica. Era la primera vez en la historia que dos grandes Estados europeos abordaban una propuesta semejante. El proyecto se convirtió en un hito en la historia de la integración jurídica, política e institucional europea. 


\section{Abstract}

At the beginning of World War II, when the French Republic was about to capitulate after the German offensive in the spring of 1940 , the allied governments of Great Britain and France debated a project for the creation of a new state: the Franco-British Union. It was the first time in history that two great European states had tackled such a proposal. The project became a milestone in the history of European legal, political and institutional integration.

\section{Palabras clave}

Cooperación, Unión, integración, proyecto, capitulación, nación, Gran Bretaña

\section{Key words}

Cooperation, Union, integration, project, capitulation, nation, Great Britain

\section{EN LA PAZ Y EN LA GUERRA...: PRESENTACIÓN}

«Para mí, Inglaterra y Francia se comportaban en la adversidad «como un solo pueblo». Esta imagen acudió a mi mente con la misma intensidad veinticinco años más tarde, cuando los dos países se enfrentaron otra vez al mismo enemigo y redacté con Salter la declaración de Unión. En 1940, el hundimiento del frente nos obligó a quemar etapas y a apuntar de inmediato hacia el más ambicioso objetivo político: que en la paz y en la guerra, de hecho y de derecho, Inglaterra y Francia no fueran sino una sola nación compuesta por los mismos ciudadanos»138.

138 MONNET, J.: Memorias. Martínez García, J. (trad.). Madrid. Instituto Universitario de Estudios Europeos y Ediciones Encuentro. 2010, p. 73. 
Con estas palabras, Jean Monnet recordaba que para él la historia nunca se repite realmente, aunque ante situaciones de la misma naturaleza reaccionaba con los mismos reflejos. La lucidez y audacia de J. Monnet han sido siempre admirables a lo largo de toda su vida, sobre todo por su reacción ante los momentos más difíciles de la historia, pero también ante los grandes hitos de la integración europea, como en la Declaración de 9 de mayo de 1950 a cargo de Robert Schumann.

En marzo de $1936 \mathrm{~J}$. Monnet se encontraba en Nueva York junto a Heinrich Brüning, antiguo canciller alemán, cuando leían en el New York Times que Alemania había ocupado la orilla izquierda del Rin. El estadista alemán reaccionó advirtiéndole que, si los Aliados no actuaban, al final terminaría produciéndose la guerra $^{139}$. En ese momento los Aliados no intervinieron, Inglaterra no quiso actuar y Francia, en aquel momento, sólo actuaba en conjunción con su aliado, por lo que tampoco hizo nada.

En ese contexto, en el que se acababa de iniciar la II Guerra Mundial, la idea de una integración europea volvía a estar en el centro del debate público, principalmente en Gran Bretaña. Todo ello después de que en la década de los 30 se volviera a la idea del «Estado-nación», en el que el totalitarismo se extendió por el continente europeo, negando derechos y libertades fundamentales ${ }^{140}$.

En este periodo inicial de la guerra, Inglaterra y Francia establecen una estrecha colaboración para hacer frente a la invasión alemana, pero la rapidez con la que suceden los acontecimientos, hará que se replanteen si la colaboración entre ambos países es suficiente. Precisamente los límites de la colaboración entre los dos países son los que dan origen a la hipótesis central del trabajo. La cooperación

139 Ibídem, p. 132. Brüning le explicó a J. Monnet que si los Aliados no actuaban Hitler se creería invencible y el Ejército alemán le seguiría.

140 SAN MIGUEL PÉREZ, E.: La civilización de los inconformistas: el ideal europeo en el pensamiento político y la acción institucional (1919-1949). Madrid. Fundación Universitaria Española. 2005, p. 107. 
entre Inglaterra y Francia no estaba funcionando y era necesario un cambio drástico en las relaciones entre ambos países para dar un vuelco a la situación, este se produciría con la propuesta de Unión Franco-Británica realizada por J. Monnet, con la que Francia podría continuar la guerra y sumar sus recursos a los de Gran Bretaña, que junto a la ayuda de Estados Unidos les darían la victoria.

En esa relación entre ambos países, se pretende retomar la fórmula de cooperación ensayada en la Gran Guerra con las Comisiones Interaliadas, que se disolvieron con la paz. Al frente de la nueva Comisión se situó J. Monnet, quien tenía una amplia experiencia de la guerra anterior. J. Monnet participó en las mismas junto a su gran amigo Arthur Salter, pero también junto a otras figuras tan relevantes como René Pleven. En la Gran Guerra, gracias a la colaboración entre los Aliados, habían conseguido corregir el desequilibrio naval, lo que resultó esencial para la victoria. En esta nueva guerra, J. Monnet sabía que el principal problema sería la superioridad aérea alemana, por lo que decidió centrar sus esfuerzos en conseguir la superioridad área de los Aliados ${ }^{141}$. La experiencia de la Comisiones en la Gran Guerra, quedaba reflejada en la reflexión que realizaba Arthur Salter al desmantelarse los Comités y que J. Monnet utiliza para explicar el método seguido en las acciones internacionales en las que participó:

«...En la medida en que los Aliados son considerados como competidores con intereses divergentes, toda comunicación de ese tipo debilita la posición negociadora del propio país. Pero en la medida que son considerados como socios, cuyos intereses son más importantes que las reivindicaciones rivales, esa comunicación puede ser a menudo esencial...»142.

Cuando la guerra alcanzó el mes de junio, J. Monnet lanzó su propuesta de Unión Franco-Británica, que vertebra y motiva el estudio de este trabajo. Una declaración escueta, pero muy innovadora, a la vez que inesperada, que constituye uno de los grandes hitos en la construcción europea. Para su estudio se ha seguido

${ }^{141}$ MONNET, J.: Memorias... cit. p. 18.

142 Ibídem, p. 85.

Attribution-NonCommercial 4.0 International (CC BY-NC 4.0). e-ISSN: 2660-552X 
el testimonio directo de sus autores, analizando cómo surgió la idea original de J. Monnet, cuáles fueron sus influencias, por qué decidió presentarla en un momento tan complejo cuando el frente francés se había hundido, cuál era su contenido, su significado y todos los acontecimientos que desencadenaron la misma.

Las fuentes principales para la realización del trabajo son las memorias de los grandes estadistas, Jean Monnet, Winston Churchill, Paul Reynaud y Charles De Gaulle, que intervinieron en este capítulo de la integración europea surgido de la propuesta de Unión Franco-Británica. Junto a estas fuentes que ofrecen los testimonios en primera persona, se utilizan un segundo tipo de fuentes que son el resultado de grandes trabajos de investigación como los de Andrea Bosco, Enrique San Miguel Pérez o Rogelio Pérez-Bustamante, entre otros, que aportan una visión analítica y reflexiva sobre los acontecimientos de la primavera de 1940.

La metodología utilizada para la realización del trabajo parte de la hipótesis central sobre los límites de la cooperación entre los países, en la que se plantea como necesaria ante una situación crítica la unión de los mismos para superarla. De este modo, se parte de la propuesta de Unión Franco-Británica como eje principal entorno al que se vertebra todo el trabajo y al que giran todas las preguntas de investigación del mismo.

Las primeras preguntas que se plantean como objeto de investigación son ¿Cuáles fueron los hechos que desembocaron en la propuesta de Unión FrancoBritánica?, ¿Cuáles fueron límites de la cooperación con los que se encontraron en la primavera de 1940, Inglaterra y Francia para frenar la invasión de Alemania? y ¿Por qué J. Monnet propone la unión de ambas naciones como solución a las limitaciones de la cooperación entre Inglaterra y Francia? Es en este punto donde surge el estudio del movimiento federalista que se genera a finales de los años 30 en Gran Bretaña y la influencia que produce el mismo. Esto conduce al análisis de la propuesta de J. Monnet y todos los acontecimientos que se suceden entono a 
ella. Todo ello demuestra la relevancia del proyecto de Unión Franco-Británica dentro del proceso de integración europea.

«La mañana del 10 de mayo de 1940 fue esplendida en toda Europa. El sol y el calor acaban de llegar por sorpresa. Temíamos ese momento que los alemanes acechaban... ${ }^{143}$.

\section{LA UNIÓN FRANCO-BRITÁNICA.}

\subsection{EL NACIMIENTO DE LA FEDERAL UNIÓN. EL FEDERALISMO BRITÁNICO}

En Inglaterra, como consecuencia de la crisis de Múnich en $1938^{144}$, que daría lugar al desmembramiento de Checoslovaquia y con ello a la pérdida para los Aliados del segundo mayor fabricante de armamento de Europa central, Skoda ${ }^{145}$, empezó a surgir un movimiento federalista. Dentro de ese movimiento destaca la publicación Union Now, de la periodista Clarence Streit, que llamaba a la organización de los federalistas en un movimiento popular. El artículo exponía la importancia que tenía construir una defensa contra el militarismo y la guerra, que representaba Alemania, que no estuviera basada en viejas alianzas defensivas, sino mediante la unión de las naciones sobre una base federal. El objetivo, era que frente a la construcción europea de Alemania, en la que las naciones se mantenían unidas por la militarización y bajo la amenaza de la guerra, se opusiera un modelo basado

143 lbídem, p. 15.

144 SELF, R. C.: Neville Chamberlain: A Biography. London. Ashate Publishing Limited. 2006, p. 6. Chamberlain fue castigado como el «Guilty Men» de Múnich, por ser un torpe ingenuamente complaciente.

${ }_{145}$ CHURCHILL, W. S.: La segunda guerra mundial. Devoto, A. (trad.). Madrid. La esfera de los Libros. 2004, p. 257. La producción de armamento de Skoda para Alemania entre agosto de 1938 y hasta la invasión de Polonia en septiembre de 1939, fue igual a la producción de todas las fábricas de armamento británicas, en el mismo periodo. 
en la democracia y la unión federal de las naciones por el consentimiento de sus pueblos $^{146}$.

Antes de la citada publicación, en otoño de 1938, Charles Kimber, Derek Rawnsley y Patrick Ransome, creaban en Londres la organización federal denominada Federal Union. Esta tendría un papel muy relevante dentro de los movimientos federalistas y del proceso de construcción europea. Esta organización tuvo un gran crecimiento, consiguiendo tener más de 225 sucursales y 15.000 miembros en todo Inglaterra ${ }^{147}$, desde su fundación hasta la primavera de 1940, en parte gracias al éxito de la publicación Union Now y al apoyo recibido por Lord Lothian y Lionel Curtis, presidente de la Chatham House. La aportación que realizarían al federalismo europeo consistiría en expresar y organizar un nuevo comportamiento político. La Federal Union define un nuevo objetivo político que no se basa en la conquista del poder nacional, sino en la construcción de una institución supranacional, una federación de naciones, que supera la idea del «Estadonación»148.

La Federal Union abogaba por que la construcción europea fuera realizada por sus tres grandes potencias, Inglaterra, Francia y Alemania, y bajo ese presupuesto lanzaron un manifiesto que recogía las principales líneas de su ideario. Con una línea de política muy potente en la que cualquier Gobierno que aceptara

146 STREIT, C. K.: Union Now. A Proposal for a Federal Union of the Democracies of the North Atlantic. New York/London. Harper \& Brothers Publishers. 1939, p. 12. Streit proponía la unión de las 15 principales democracias para hacer frente al riesgo que suponía la militarización de Alemania y su visión de una Europa unida bajo la amenaza de la guerra. En el que tuvieran una ciudadanía común, un Ejército común, un Mercado Común y un sistema postal.

147 BOSCO, A.: Democracy, Federalism, the European Revolution, and Global Governance. Newcastle. Cambridge Scholars Publishing. 2020, p. 164.

148 BOSCO, A.: June 1940, Great Britain and the First Attempt to Build a European Union. Newcastle. Cambridge Scholars Publishing. 2016, p. 2. Esta idea de la federación europea era una «idea de la razón», abstracta en sí misma, pero sin duda suponía un primer paso en el proceso de construcción europea. Una nueva fórmula política más moderna que institucionalizaba la división política.

Ihering. Cuadernos de Ciencias Jurídicas y Sociales N ․ㅡ 4 (2021)

DOI: https://doi.org/10.51743/ihering.275 
una declaración de los derechos del hombre podría formar parte de la Federación. Con esta declaración abrían expresamente la posibilidad de que Alemania se uniera a la Federación, sí conseguía vencer la idea de la superioridad racial y aceptaba la declaración de derechos del hombre. Sin embargo, ante la previsible ofensiva de alemana, desde la primavera de 1940, la Federal Union decidió restringir la unión solo a Inglaterra y Francia, dejando fuera a Alemania ${ }^{149}$.

En el periodo de tiempo que abarca desde la crisis de Múnich hasta la caída de Francia, el federalismo británico proporcionaría una base teórica para la construcción europea, mediante la creación de una extensa producción literaria. A su contribución participaron figuras de diferentes ámbitos de la sociedad como intelectuales, políticos o eclesiásticos ${ }^{150}$ que abarcaban desde el pensamiento liberal hasta el socialista. Entre sus figuras más representativas podemos encontrar al historiador Arnold Toynbee, que fue director del Royal Institute of Internacional Affairs creada dentro de la Chatham House, o Lionel Robbins, profesor de la London School of Economics. Estos influyeron decisivamente en el pensamiento político del momento, llegando a conseguir que apoyaran abiertamente el proyecto federalista políticos como Chamberlain, Halifax, Churchill, Eden o Attlee ${ }^{151}$.

En mayo de 1939, a cargo de Toynbee, la Foreign Office creó un departamento de investigación para proporcionar información relativa a aspectos históricos sobre la guerra y cuestiones relacionadas con la paz, denominado Foreign Research and Press Service. El Gobierno británico necesitaba un grupo de hombres que trabajara en un proyecto que predijera el escenario de postguerra para

149 LIPGENS, W. (Ed.): Documents on the History of European Integration 2. Plans for European Union in Great Britain and in Exile 1939-1945. Berlin/New York. Walter de Gruyter. 1986, pp. 57-58. Recoge los principios de la Federal Union en «The aims of Federal Union».

150 BOSCO, A.: Democracy... cit. p. 165. Las figuras que destacaron entre el federalismo británico en el periodo de 1938-1940 son conocidas en la actualidad como la «Anglo-Saxon Federalist School».

151 Ibídem, p. 166. El proyecto federalista fue publicado en los periódicos nacionales más importantes de Gran Bretaña dando cobertura al debate surgido en torno al federalismo.

Attribution-NonCommercial 4.0 International (CC BY-NC 4.0). e-ISSN: 2660-552X 
conseguir una paz duradera. Este departamento comenzó a trabajar en septiembre de 1939, cuando el Gobierno británico se dirigió a la Chatham House para buscar ideas acerca de un posible acuerdo de paz cuando finalizase el conflicto. La Chatham House, formó un grupo de académicos, intelectuales y empresarios que realizaron un seminario sobre historia donde estudiaron el pasado para realizar un proyecto de cara al futuro' ${ }^{152}$.

La Chatham House con Lionel Curtis a la cabeza jugó un papel decisivo para convencer a la Foreign Office de la razonabilidad de la Unión Franco-Británica introduciendo ideas de una reorganización federalista después de la guerra. Estas ideas de Curtis influirían sobre todo en Toynbee al frente del departamento de investigación de la Foreign Office ${ }^{153}$. Toynbee estaba desarrollando una propuesta que suponía la puesta en común entre Inglaterra y Francia «del control de los servicios económicos y militares, del comercio exterior y de una ciudadanía en común»154. Esta se materializaría en el "Act of Perpetual Association between the United Kingdom and France», que redactó el propio Toynbee, junto a su ayudante Alfred Zimmern y que suponía un Tratado Constitucional que establecía como núcleo de la Unión Europea la unión Franco-Británica ${ }^{155}$.

Finalmente, el Acta elaborada por Toynbee contenía la creación de un organismo común responsable de la política militar, exterior y económica de la Unión, con una ciudadanía común. El organismo común era un «Consejo Supremo»

152 BOSCO, A.: June 1940... cit. p. 234. La Foreign Office dotó a la Chatham House con un presupuesto anual de 80.000 libras, que el Parlamento redujo a la mitad. El nuevo organismo con sede en Oxford empezó a trabajar en septiembre de 1939 con Toynbee como director y Curtis como presidente de la Chatham House.

153 Ibídem, p. 235. La influencia de Curtis sobre Toynbee se deja ver en el memorándum que realizó este último denominado «Second Thoughts on a Peace Settlement» que dirigió a Halifax y a los miembros de la Chatham House.

154 PÉREZ-BUSTAMANTE, R.: Historia política de la Unión Europea 1940-1945. Madrid. Dykinson 1995, p. 40.

${ }^{155}$ BOSCO, A.: June $1940 \ldots$ cit. p. 239. Toynbee redactó el Acta junto a Zimmern en un plazo de 10 días.

Ihering. Cuadernos de Ciencias Jurídicas y Sociales N.ㄴ 4 (2021)

DOI: https://doi.org/10.51743/ihering.275 
que se reuniría periódicamente bajo la presidencia de los primeros ministros de ambos países y apoyada por una Secretaría permanente. Desde el punto de vista de la defensa, creaba un Comité de Defensa Franco-Británico. Y por último, creaba un organismo económico centrado en la transición entre la economía de guerra a la de paz ${ }^{156}$.

La Foreign Office empezó en marzo de 1940 a examinar seriamente el Acta de Asociación, creando ad-hoc un Comité interministerial, presidido por Maurice Hankey, para llevarlo a una Constitución. La Foreign Office empezaba a trabajar especialmente en esta idea federal para crear unas nuevas relaciones, entre Inglaterra y Francia, que trasformaran la cooperación bélica entre ambos países, en una unión política estable y permanente ${ }^{157}$. Este movimiento por parte de la Foreign Office no hubiera sido posible sin el apoyo popular que se generó entre la sociedad británica hacia el federalismo, impulsado por la Federal Union que sirvió de catalizador de las ideas que se habían extendido entre la sociedad británica en los años precedentes ${ }^{158}$.

\subsection{LA PROPUESTA DE UNIÓN FRANCO-BRITÁNICA.}

En la segunda semana del mes de junio de 1940, la alianza entre Inglaterra y Francia estaba a punto a de romperse. Los franceses se debatían entre continuar la guerra desde África, posición que defendía el presidente P. Reynaud con la ayuda del general De Gaulle, o capitular y solicitar el armisticio a Alemania, en esta posición se encontraba el mariscal Pétain y el general Weygand. Mientras los

156 Ibídem, p. 240. Finalmente usaron la palabra «Act» y no «Pact» 0 «Treaty» por ser un término más ajustado a los términos de la política interna. Del mismo modo usaron el término «Association» y no «Union» por la gravedad del momento en el que se desarrollaba el proyecto.

157 BOSCO, A.: Democracy... cit. p. 166.

158 BOSCO, A.: June 1940... cit. p. 5. La extensión del federalismo en Inglaterra en el periodo entre las dos guerras mundiales se debió en parte al «Round Table Movement», creado en 1909 por el «Milner's Kindergarten», con el fin de llevar a cabo una reforma institucional del Imperio en líneas federales.

Attribution-NonCommercial 4.0 International (CC BY-NC 4.0). e-ISSN: 2660-552X 
británicos, por primera vez empezaban a tener dudas de que Francia no solicitase el armisticio por separado. Churchill ya había informado de la necesidad de reforzar la defensa de la isla y se negaba a mandar ninguno de los 25 escuadrones de la Fuerza Aérea que habían considerado como necesarios para mantener el dominio de los cielos en Inglaterra.

J. Monnet, que se encontraba en Londres como presidente del Comité de Coordinación Franco-Británico, era conocedor de lo complicado de la situación. Sabía por su experiencia en las Comisiones Interaliadas en la Gran Guerra y la lentitud con la que se estaba llevando la coordinación ${ }^{159}$ entre ambos países, que el acuerdo del 28 de marzo podía no ser suficiente para conseguir frenar la ofensiva de Alemania. Por ello, había empezado a trabajar en un proyecto que supusiera una mayor unión, buscando que los países realizaran un esfuerzo más estrecho y unieran sus destinos con un objetivo común.

En una entrevista concedida por J. Monnet al historiador canadiense John Coins, le comentó como en la primavera de 1940 le habían influenciado en la formación de su plan estratégico los artículos que estaban publicando los periódicos británicos y en especial The Times, que apoyaban desde el comienzo de las hostilidades la necesidad de una unión económica y política amplia entre Francia e Inglaterra. J. Monnet también había seguido de cerca las reuniones que Toynbee desde la Foreign Research and Press Service estaba realizando con la Chatham House y tenía conocimiento del Act of Perpetual Association que había redactado Toynbee ${ }^{160}$.

En la segunda quincena de mayo tras el rápido avance de las tropas alemanas, J. Monnet se había dado cuenta que la moral de los Aliados era pésima y que la coalición carecía de alma. En todo el tiempo que había trascurrido desde el

159 MONNET, J.: Memorias... cit. p. 17. J. Monnet se lamentaba que, para conseguir el Balance del potencial aéreo de los dos países, necesario para que Estado Unidos aumentara su producción hubiera necesitado 4 meses.

160 PÉREZ-BUSTAMANTE, R.: Historia política de la Unión... cit. p. 40.

Ihering. Cuadernos de Ciencias Jurídicas y Sociales N. 4 (2021)

DOI: https://doi.org/10.51743/ihering.275 
inicio de la guerra, no habían propuesto unos objetivos militares claros, lo que dificultaba conseguir un esfuerzo común sin un objetivo compartido, más allá de frenar la invasión alemana y luchar por la libertad ${ }^{161}$.

Como consecuencia del embarque de las tropas Aliadas en Dunkerque y la fragilidad de la Alianza, J. Monnet ya había realizado alguna propuesta al propio Churchill, en relación con unificar la Fuerza Aérea británica y francesa bajo un mismo mando ${ }^{162}$. J. Monnet era conocedor de la capacidad de ambas Fuerzas, debido al Balance que había realizado para el Comité de Coordinación. Si las dos Fuerzas se unían en una sola, conseguirían contrarrestar la superioridad alemana, que se manifiesta en 3 contra 1 con la francesa ${ }^{163}$, pero que juntas era sólo de 1 contra 1,5. En Dunkerque había quedado probado que, ante la igualdad de Fuerzas, ellos eran superiores, pero no obtuvo respuesta por parte de Churchill.

El 13 de junio ante la entrada de los primeros tanques alemanes en Francia, J. Monnet decidió que el momento de llevar a cabo su proyecto de Unión había llegado. Por ello, junto con su compañero del Comité Arthur Salter, el cual conocía de su experiencia en los Comités Interaliados, ultimaban un informe con la extensión de cinco hojas y bajo el nombre en inglés "Anglo-French Unity» ${ }^{164}$, en el que examinaban los posibles escenarios que se podían encontrar, con la misma conclusión en todos. Si querían conseguir la victoria final en la guerra era necesaria la unión total entre Inglaterra y Francia. El texto abogaba por la unión de ambas

${ }^{161}$ MONNET, J.: Memorias... cit. p. 19. Según J. Monnet: «lo que faltaba era la conciencia clara del peligro mortal en que ponía al mundo la voluntad de hegemonía total de Hitler».

162 DUCHÊNE, F.: Jean Monnet. The first statesman of interdependence. New York/London. W. W. Norton \& Company. 1994, p. 77. El 6 de junio J. Monnet se encontró con Churchill al que instó a fusionar las Fuerzas Aérea de Inglaterra y Francia, con la que conseguirán la superioridad y vencer a los alemanes en el aire. 163 REYNAUD, P.: Memorias de... sobre la catástrofe de Francia. Madrid. Edica. 1945, p. 33. El informe de Weygand sobre la situación en el frente, ante el Comité de Guerra del 25 de mayo, relata que estaban combatiendo en una desventaja de 3 contra 1 contra la Luftwaffe.

${ }^{164}$ MONNET, J.: Memorias... cit. p. 20. Bajo el título en inglés «Anglo-French Unity» esa misma noche J. Monnet modificó «Paris may fall at once» por «Paris has fallen». 
naciones, de modo que sí finalmente las tropas retrocedían hasta el punto que toda Francia fuera invadida, esta podría continuar la guerra junto a Inglaterra desde cualquier isla de resistencia. En el peor de los escenarios la Flota, la Aviación, el material y las tropas se fusionarían y seguirían luchando juntas, pasara lo que pasara, hasta que los recursos de las dos naciones, superiores a los de Alemania, junto a Estado Unidos les dieran la victoria.

La propuesta así planteada por J. Monnet, presentaba el problema de que si únicamente se abordaba desde un punto de vista militar no perduraría ${ }^{165}$ en el tiempo, tal como pasó con los Comités Interaliados en la Gran Guerra, por eso la presentó con una perspectiva en la que unían los destinos de los dos países. En el documento recogían la necesidad de que las dos naciones actuaran y lucharan como un único pueblo, de modo que los intereses de uno fueran los intereses del otro. Si Francia caía, había que evitar que Inglaterra fuera invadida. Pero lo más importante era que recogía la necesidad de que los dos Gobiernos hicieran una declaración conjunta en la que se comprometieran a la reconstrucción de las regiones destruidas, uniendo sus intereses de modo que "los dos Gobiernos se fusionan y forman un solo Gabinete con la reunión de los dos Parlamentos» ${ }^{166,}$ mientras durase toda la guerra.

En ese momento, la propuesta no concretaba más, porque en un principio no estaba destinada para dirigírsela a Churchill, sino que se encontraba en un momento anterior, destinada para convencer a los estadistas y discutirla, para ir puliéndola. Sin embargo, debido al rápido deterioro de la situación, donde Francia empezaba a pensar en el armisticio e Inglaterra en la defensa nacional separando así sus intereses comunes, era urgente que la propuesta llegara a manos de

165 Ibídem, p. 21. J. Monnet pensaba si sólo se limitaba a lo militar, ni los mejores estrategas hubieran conseguido: «fusionar unas fuerzas que hubieran perdido su confianza en el futuro».

166 Ibídem, p. 21.

Ihering. Cuadernos de Ciencias Jurídicas y Sociales N.ำ 4 (2021)

DOI: https://doi.org/10.51743/ihering.275 
Churchill. De este modo los británicos conseguirían las garantías que necesitaban de Francia para que continuara en la guerra.

\subsection{SIR WINSTON CHURCHILL Y LA PROPUESTA DE 1940}

En algunas ocasiones J. Monnet ya había intentado que sus ideas fueran escuchadas por Churchill, pero solía reusarlas porque tenían una perspectiva de futuro y el primer ministro estaba centrado en la guerra y en la acción inmediata ${ }^{167}$, por lo que no podía ser él quien tratara el proyecto directamente con Churchill. Fue entonces cuando su amigo Desmond Morton, que además era el secretario del primer ministro, le dio el consejo de que fuese Chamberlain quien hablara con él ${ }^{168}$ y le dijera que quería que la propuesta fuera trasladada al Gabinete, así al menos se debatiría.

De ese modo J. Monnet, el 14 de junio por la mañana, se puso en contacto con su amigo Horace Wilson, que era el jefe de Gabinete de Chamberlain, y le comentó la importancia de la unión entre Inglaterra y Francia, al cual le convenció rápidamente la propuesta. Este le preguntó si con la Unión se refería a una unión completa con un solo Gabinete, Parlamento y Ejército. J. Monnet le contesto afirmativamente y su amigo le prometió que haría lo posible para que Chamberlain convenciera a Churchill ${ }^{169}$.

Esa misma noche habló otra vez con Horace Wilson, había conseguido convencer a Chamberlain, el cual le había pedido a Churchill que la propuesta fuera debatida por el Gabinete de Guerra. También habían tenido contacto con Lord

167 Ibídem, p. 21. Churchill le había dicho a J. Monnet en otras ocasiones: «Yo hago la guerra» $y$ «usted viene a hablarme del futuro».

168 Ibídem, p. 22. Desmond Morton, le dijo a J. Monnet que si él fuese el jefe de Gobierno francés Churchill le escucharía sin ningún problema, pero no lo era y veía difícil que lograra que le escuchase porque sencillamente él era así. Sin embargo, Churchill tenía en una alta estima a su predecesor Chamberlain.

169 Ibídem, p. 22. 
Halifax ${ }^{170}$, que en ese momento era el jefe de la Foreign Office. J. Monnet sabía que para debatirlo en el Gabinete de Guerra se tenía que redactar un documento que estuviera en el orden del día. Se enteró que el encargado era Vansittart, el secretario permanente de la Foreign Office, por lo tanto, él sería quien redactaría el documento final de la propuesta para ser debatido, así que que al día siguiente se pusieron en contacto con él. Finalmente, entre Vansittart, Morton, Salter, Pleven ${ }^{171}$ y Monnet redactaron el documento que se debatiría. Entre los cinco redactaron un «proyecto de declaración de unión indisoluble»172. En él se creaba una ciudadanía y moneda común, una unión aduanera y la reparación equitativa de los daños sufridos por la guerra.

Según cuenta De Gaulle en sus memorias de guerra, ante las reticencias que pudiera mostrar Churchill al proyecto, en la mañana del 16 de junio, fueron a su encuentro J. Monnet y Corbin, que era el embajador de Francia en Londres. De Gaulle, acababa de llegar a Londres desde Brest vía Plymouth cumpliendo la misión que le había en cargado P. Reynaud el día 14. El domingo 16, tenía previsto entrevistarse con Churchill, para asegurar la colaboración británica en el traslado a África. Entre los dos le expusieron la situación, al Gobierno británico ya le había llegado la petición que se aprobó en el Gabinete de Guerra francés del día 15 de junio, que solicitaba autorización para negociar las condiciones del armisticio con Alemania, sin embargo, todavía no sabían cuál sería la decisión que iban a tomar los británicos, aunque creía que, si Francia era capaz de ofrecer garantías sobre la Flota francesa, estos aceptarían. Además, esa misma mañana tenía previsto celebrarse en Francia un Consejo de ministros que sería decisivo.

En ese momento fue cuando le expusieron la idea del proyecto de Unión que habían llevado a cabo, en el que el Gobierno británico propondría al francés

170 Ibídem, p. 22. David Margersson del Partido Conservador se puso en contacto con Halifax para presentarle la propuesta de Unión.

171 Ibídem, p. 22. Pleven era el adjunto de J. Monnet en el Comité de Coordinación. 172 Ibídem, p. 22. 
una unión de los destinos de ambos pueblos. El proyecto supondría una inyección de moral en el estado de ánimo de los franceses, reforzaría la posición de P. Reynaud de trasladarse a África y los ministros franceses se replantearían no abandonar la guerra. Ante aquella exposición, De Gaulle examinó el texto que habían preparado y rápidamente se dio cuenta de la dificultad que entrañaba un plan tan ambicioso ${ }^{173}$. Las dificultades que planteaba el proyecto requerían de largos debates entre las partes, pero el ejercicio de solidaridad que suponía la propia propuesta por parte del Gobierno británico y la urgencia del momento, podía dar a P. Reynaud el argumento que necesitaba para convencer a sus ministros de trasladarse a África ante el Consejo de ministros decisivo. De ese modo, De Gaulle les prometió hacer todo lo posible para que Churchill lo aceptase.

\subsection{LOS BRITÁNICOS ANTE EL MAYOR ACTO DE SOLIDARIDAD DE LA HISTORIA}

En la mañana del 16 de junio, se reunían en el Carlton Club De Gaulle, J. Monnet, Corbin y Churchill. El primer ministro británico se encontraba preocupado por el destino de la Flota francesa. Por su parte, De Gaulle le aseguraba que el almirante Darlan, no dejaría nunca que Alemania utilizara su Flota, pero la única manera que tenían de estar seguros, era que Francia siguiera en la guerra. En ese momento, el general le reprochó a Churchill su actitud en la reunión de Tours el día 13, donde su resignación había dado alas a los partidarios del armisticio ${ }^{174}$. A continuación, De Gaulle le mencionaba a Churchill el proyecto de unión entre

173 GAULLE, CH. de.: Memorias de... cit. p. 63. De Gaulle al examinar el texto vio que excluía la posibilidad de una rápida ejecución, era prácticamente imposible refundir Inglaterra y Francia a través de un intercambio de notas en un día.

174 Ibídem, p. 64. Según De Gaulle los partidarios del armisticio utilizaron la respuesta de Churchill en la reunión de Tours para decir: "No nos queda otra alternativa» $y$ «los propios ingleses nos han dado su consentimiento», lo que no les ayudaba para salir de la crisis. 
Inglaterra y Francia.

Churchill comentó tener conocimiento del proyecto, pero mostraba reticencias al respecto pensado que una obra así resultaría demasiado compleja ${ }^{175}$. Sin embargo, De Gaulle le remarcó los efectos inmediatos que tendría el mismo sobre la situación francesa y la posibilidad de que Francia continuara la guerra. Tras un rato de discusión, finalmente, De Gaulle consiguió convencer a Churchill, el cual convocó el Gabinete de Guerra de inmediato.

Tras finalizar la reunión en el Carlton Club, De Gaulle, telefoneó a P. Reynaud para decirle que a primera hora de la tarde le enviaría una importante comunicación por parte del Gobierno británico. P. Reynaud le dijo que el Consejo de ministros de la mañana se había suspendido y se iba a celebrar por la tarde a las 17 horas, pero que no podría retrasarlo más allá de esa hora.

La reunión se celebraba en Downing Street, donde Churchill presentaba la propuesta ante el Gabinete de Guerra. El primer ministro se sorprendió por la gran acogida que recibió por parte de Attlee, Ernest Bevin y Sir Archibald, que como consecuencia del debate federalista que se había instalado en la sociedad británica, ya se habían declarado a favor de la idea de una federación europea basada en un núcleo Franco-Británico ${ }^{176}$. Mientras en el despacho de Morton, contiguo al de la celebración del Consejo, se encontraban De Gaulle, J. Monnet y Corbin donde los ministros entraban y salían continuamente proponiéndoles cambios en el texto, que no afectaban al fondo del mismo, y los cambios que restaban precisión a la propuesta le sumaban al carácter imponente de la misma ${ }^{177}$. Al final, la sesión del Gabinete terminó durando dos horas, hasta que concluida la misma y encabezados

175 Ibídem, p. 65. Churchill, le dijo a De Gaulle que había tenido conocimiento del proyecto por Lord Halifax, pero que era «una obra de mucha envergadura».

176 BOSCO, A.: Democracy... cit. pp. 166-167.

177 MONNET, J.: Memorias... cit. p. 28. Según Monnet mientras estaban realizando los cambios que les proponían los ministros Churchill le dijo: «En un momento tan grave... nadie podrá decir que nos ha faltado imaginación».

Ihering. Cuadernos de Ciencias Jurídicas y Sociales N.ำ 4 (2021)

DOI: https://doi.org/10.51743/ihering.275 
por Churchill todos sus miembros entraron en el despacho y exclamaron « $i$ Estamos de acuerdo!»178.

Con la propuesta ya aprobada, Pleven se encargaba de traducirla al francés, el general De Gaulle se ponía en contacto con P. Reynaud y le comunicaba la noticia dictándole el documento, ya que no podía esperar a que se lo llevase ${ }^{179}$. Al finalizar el dictado del mismo, el propio Churchill se ponía al teléfono para decirle que resistiera y que a la mañana siguiente se veían en Concarneau. Terminada la comunicación, Churchill le prestó un avión a De Gaulle, para que le llevara el texto de la declaración al presidente francés.

La declaración definitiva de Unión Franco-Británica, constaba de una única hoja. En ella, los Gobiernos de Reino Unido y Francia declaraban la unión indisoluble de las dos naciones ${ }^{180}$ con el objetivo de defender la libertad frente a un sistema, el alemán, que reducía la humanidad a la esclavitud.

Las dos naciones se fusionaban en una sola, pasando a ser la Unión Franco-Británica. Además, se creaba una ciudadanía común, de modo que todo ciudadano británico gozaría de la ciudadanía francesa y viceversa.

Respecto a los daños que sufrieran los dos países como consecuencia de la guerra, ambos pondrían en común sus recursos que serían utilizados como un todo para la reparación indistinta de los mismos. Se dejarían de usar las monedas

178 GAULLE, Ch. de.: Memorias de guerra. Madrid. La esfera de los Libros. 2005, p. 64.

179 MONNET, J.: Memorias... cit. p. 28. Según De Gaulle llamaba a P. Reynaud a las 16:30, media hora antes de que se celebrara el Consejo de ministros francés a las 17 horas. Mientras De Gaulle le dictaba el documento, cuentan el general Spears y Campbell, que a medida que iba escribiendo las líneas del documento se le iba iluminando la cara a P. Reynaud.

180 MACMILLAN, H.: The Blast of War. 1939-1945. London/Melbourne/Toronto. New York, Harper \& Row. 1967, p. 11. Harold Macmillan mantenía que la propuesta de Unión no se limitaría a un futuro inmediato, sino que estaba destinada a ser para siempre, pues había sido refrendada por los tres partidos representados en la Cámara de los Comunes. 
de cada país y se crearía una moneda común.

Durante el transcurso de la guerra, los dos Gabinetes de Guerra se unirían en un solo Gabinete a partes iguales, que actuaría desde donde mejor cumpliera su función. Además, los dos Gobiernos se integrarían en uno solo y los dos Parlamentos se unirían en un único Parlamento, ambos por mitades. Como consecuencia de ello, redactarían una Constitución de la Unión en la que crearían nuevos órganos comunes para la defensa, la política exterior y los asuntos económicos.

Por último, los Ejércitos de las dos naciones se colocaban bajo un Mando único y a la vez hacían un llamamiento en nombre de la Unión a Estado Unidos para que reforzara el potencial industrial para armar a este Ejército ${ }^{181}$.

\subsection{FRANCIA, EL GRAN DESASTRE. LA DECISIÓN QUE} CAMBIARÍA LA HISTORIA DE EUROPA

El 16 de junio a las 11 de la mañana comenzaba el Consejo de ministros decisivo para el futuro de Francia y Europa. El Consejo se iniciaba con la dimisión del mariscal Pétain, el cual, mediante una carta, exponía que el retraso en la solicitud para pedir el armisticio motivaba su dimisión. Cuando se disponía a abandonar la sala, el presidente de la República, Lebrun, se lo impidió, al igual que hizo el día anterior con P. Reynaud, este no podía aceptar que el mariscal dimitiera ${ }^{182}$. En ese momento intervino P. Reynaud, quién le explicó que ya había

181 PHILIP, O.: Le probleme de I'Union Européenne. Neuchâtel. Baconnière. 1950, pp. 167-168. Es una propuesta que no recoge los principios de la Sociedad de Naciones, cuyo objetivo es crear una unión real y efectiva.

182 REYNAUD, P.: Memorias de... cit. p. 57. Lebrun le dijo a Pétain muy emocionado: « $i$ No es posible que haga usted eso, precisamente en unos momentos tan graves...!». 
pedido la autorización a los británicos para solicitar el armisticio, conforme se había aprobado en el Consejo anterior, y que estaba esperando la respuesta que recibiría esa misma tarde. Por lo que se aplazó la reunión hasta las 17 horas.

A primera hora de la tarde, P. Reynaud recibía en su despacho por manos del embajador británico, sir Ronald Campbell, el telegrama del Gobierno británico autorizando la solicitud de las condiciones del armisticio con Alemania, con la condición de que la Flota francesa se enviara a puertos ingleses mientras durasen las negociaciones entre los dos países ${ }^{183}$. P. Reynaud comentó que, si accedían a esa petición, Tunicia quedaría expuesta a Italia durante todo el periodo de negociaciones. Poco después, volvía a recibir otro telegrama en el que los británicos querían ser informados sobre las condiciones del armisticio.

Con la confirmación por parte del Gobierno británico, los franceses ya tenían vía libre para solicitar las condiciones del armisticio a Alemania, quedaba así anulado el acuerdo del 28 de marzo por el que Francia e Inglaterra se comprometían a no solicitar las condiciones de paz con Alemania por separado. Sin embargo, como consecuencia de la reunión de De Gaulle con Churchill en el Carlton Club, en la que el general conseguía convencer al primer ministro británico para aprobar el proyecto de Unión, daba la orden de que anularan los dos telegramas que habían enviado ${ }^{184}$. De ese modo, una hora después de haber recibido P. Reynaud los dos telegramas con la confirmación, Campbell y Spears volvían para pedirle que los devolviera y comunicarle que el Gobierno británico no autorizaba ninguna gestión con el enemigo.

Después de finalizar la reunión entre De Gaulle y Churchill, el general llamaba a P. Reynaud para comunicarle que el Gobierno británico iba a proponer al Gobierno francés la unión entre Francia e Inglaterra, todavía tenía que ser aprobado

183 Ibídem, p. 57. El telegrama que fue entregado por el embajador británico y el general Spears, que autorizaba al Gobierno francés a solicitar las condiciones del armisticio, añadía que el Gobierno británico estaba dispuesto a continuar la guerra y que quedaban al margen de cualquier tipo de negociación con Alemania.

184 GAULLE, Ch. de.: Memorias de... cit. p. 65. 
en el Gabinete de Guerra británico, cosa que sucedería poco después. P. Reynaud le insistió en que necesitaba el texto de la propuesta para antes de las 5 de la tarde porque no podía retrasar más el Consejo de ministros. P. Reynaud aceptó el proyecto con gran satisfacción, aunque todavía tendrían que discutir los detalles de su aplicación, pues suponía un argumento para continuar con la guerra junto con Inglaterra. La unión con Inglaterra suponía para el presidente la independencia de Francia, mientras que el armisticio con Alemania suponía la esclavitud del país ${ }^{185}$. Justo antes de la reunión del Consejo, P. Reynaud volvía recibir la llamada de De Gaulle confirmándole que había sido aprobado el proyecto y le dictaba el contenido del mismo ${ }^{186}$.

Con el documento de la propuesta en poder de P. Reynaud daba comienzo el Consejo de ministros decisivo. El Consejo se iniciaba con la lectura de la respuesta del telegrama que Roosevelt había enviado en contestación a la petición de ayuda francesa. El presidente norteamericano elogiaba el valor de las tropas francesas y ponía en valor la ayuda que habían enviado a los Aliados, pero no se podía comprometer militarmente, pues eso era competencia del Congreso estadounidense ${ }^{187}$. A continuación, P. Reynaud explicó lo sucedido con los telegramas británicos y su negativa a autorizar la solicitud del armisticio. Y por último, pasó a explicar delante de todos sus ministros la propuesta de Unión entre los dos países que había aprobado el Gabinete británico ${ }^{188}$.

185 KERSHAW, I.: Hitler. 1936-1945. Barcelona. Ediciones península. 2000, pp. $245-$ 246. El totalitarismo nazi, suponía el sometimiento de la población a un régimen de dependencia colonial.

186 MONNET, J.: Memorias... cit. p. 30. Según J. Monnet el general Weygand intervino todas las comunicaciones entre De Gaulle y el presidente P. Reynaud, lo que hizo que precipitase su ofensiva.

${ }_{187}$ REYNAUD, P.: Memorias de... cit. p. 58. El telegrama decía: «Estoy seguro de que comprenderá usted que estas declaraciones no suponen ningún compromiso de carácter militar. Solamente al Congreso corresponde aprobar medidas de esa naturaleza».

188 Ibídem, p. 58.

Ihering. Cuadernos de Ciencias Jurídicas y Sociales N.ำ 4 (2021)

DOI: https://doi.org/10.51743/ihering.275 
P. Reynaud leyó hasta dos veces el documento de la propuesta y declaró estar totalmente a favor de la misma, concluyendo que había quedado al día siguiente con Churchill en Concarneau para debatir los detalles de la misma. Sin embargo, la propuesta cogió por sorpresa a los ministros que estaban esperando la respuesta afirmativa a la solicitud del armisticio ${ }^{189}$.

El ministro Chautemps, que ya en el Consejo de ministros anterior había maniobrado hábilmente para que el Gabinete aprobara la solicitud del armisticio con Alemania, se mostró contrario a la propuesta, argumentando que «Inglaterra quería convertir a Francia en un dominio»190. Y se reiteró en su posición de solicitar el armisticio a Alemania.

Por su parte, el ministro del Interior Mandel, se mostró a favor de la propuesta de Unión de las dos naciones y se mostró asombrado ante la actitud de los ministros que se mostraban en contra del proyecto. No podía entender que prefirieran ser una región alemana a un domino británico ${ }^{191}$. Chautemps, que se mostraba indignado, le replicaba diciendo que no le diera lecciones. Por su parte, Ybarnegaray manifestaba abiertamente que prefería ser una provincia nazi, pues sabía lo que significaba, sin embargo, el proyecto de Unión dejaba muchas dudas.

Otros ministros se quejaban de que la unión de ambas naciones no era en un plano de igualdad, pues los franceses serían ciudadanos del Imperio británico, pero no de Gran Bretaña, mientras que por el contrario, los británicos sí serían ciudadanos de Francia. Lo que demostraba que los ministros no entendían la magnitud de la propuesta, pues el texto recogía claramente una ciudadanía común en un plano de igualdad ${ }^{192}$.

La facción derrotista, que estaba encabezada por el mariscal Pétain tenían

189 CHURCHILL, W. S.: La segunda guerra... cit. p. 541.

190 REYNAUD, P.: Memorias de... cit. p. 58. A P. Reynaud le resultaba curioso que a Chautemps le resultara tan indígnate la idea de unión con Inglaterra y no la de poner a Francia a disposición de Alemania.

${ }_{191}$ CHURCHILL, W. S.: La segunda guerra... cit. p. 541.

192 Ibídem, p. 542.

Attribution-NonCommercial 4.0 International (CC BY-NC 4.0). e-ISSN: 2660-552X 
claro que no iban aceptar la propuesta, pues pensaban, como había dicho el general Weygand en más de una ocasión, que después de que Francia cayera «en tres semanas, a Inglaterra le retorcerán el cuello como a un pollo»193. El mariscal Pétain pensaba que Inglaterra sin Francia estaba muerta y no tenía sentido unirse a ella.

Al final, ante la situación y viendo que no había acuerdo sobre la unión, uno de los ministros propuso que se votara solicitar el armisticio, por lo que Lebrun, siguiendo su criterio de mayorías dio paso a la votación, que fue aprobada por «14 votos contra 10 », aunque también se ha dicho que fue por «13 votos contra 11 », la verdad es que según $\mathrm{P}$. Reynaud nadie quería reconocer que votó a favor, pero que el resultado daba igual, lo importante era que habían ganado los partidarios de solicitar el armisticio ${ }^{194}$. De este modo, quedaba aprobada la propuesta de solicitar el armisticio a Alemania. Como el Gobierno británico había cancelado los dos telegramas, estos no se tuvieron en cuenta, por lo que solicitarían el armisticio sin ninguna condición por parte de Inglaterra e incumpliendo el acuerdo del 28 de marzo. Los partidarios del armisticio consiguieron que el proyecto de Unión ni siquiera se votase en el Consejo de ministros francés.

Tras la finalización de la votación, P. Reynaud solicitaba la suspensión del Consejo para presentar su dimisión como presidente ante una política que él no podía llevar a cabo. Lebrun le dijo que continuase ${ }^{195}$, pero en esta ocasión la decisión de P. Reynaud era definitiva. Por ello, propuso que fuera Pétain quien formara el nuevo Gobierno. El mariscal era el principal promotor de la solicitud del

193 Ibídem, p. 542.

194 REYNAUD, P.: Memorias de... cit. p. 58. Durante el proceso de Riom, el presidente de la República declaró que la mayoría de los ministros ya tenían decidido que querían solicitar el armisticio.

195 Ibídem, p. 58. Lebrun estaba dispuesto a mantener a P. Reynaud en el cargo si este estaba dispuesto a seguir lo aprobado por la mayoría, pero para P. Reynaud, según les explicó a los presidentes del Senado y de la Cámara, no podía llevar a cabo tal política por considerarla contraria al honor y al interés de Francia, sino que les correspondía a quienes encarnaban esos puntos de vista contrarios al suyo, es decir, el mariscal Pétain.

Ihering. Cuadernos de Ciencias Jurídicas y Sociales N.ำ 4 (2021)

DOI: https://doi.org/10.51743/ihering.275 
armisticio y por tanto quien mejor encarnaba esa política.

Con esta decisión, P. Reynaud dejaba la presidencia del Gobierno francés y con ello las esperanzas de que Francia se trasladara a África para continuar la guerra. El proyecto de Unión Franco-Británica que hubiera cambiado el destino de Francia y Europa, no fue aprobado, malogrando así el primer proyecto de integración europeo. La idea que partía de J. Monnet como una propuesta en la que Inglaterra, en un acto de solidaridad, ofrecía la unión con Francia, fue mal interpretada por los partidarios del armisticio, que lo trataron como un plan de último minuto, utilizado para que Francia pasara a su dominio ${ }^{196}$.

Mientras esa misma noche del 16 de junio, el mariscal Pétain formaba un nuevo Gobierno, por encargo de Lebrun ${ }^{197}$. Churchill ya sabía que tendrían que continuar la guerra sin Francia ${ }^{198}$. Ese mismo día por la noche, el Gobierno de Pétain solicitaba las condiciones del armisticio a Alemania. Según Pétain solicitó el armisticio de acuerdo con los jefes militares limitándose a «cumplir un acto necesario y salvador $\$ 199$.

Mientras en Londres, el general De Gaulle se preparaba para liderar la Resistencia francesa y hacer un llamamiento a la Francia libre. El 17 de junio por la tarde se ponía en contacto con Churchill y le explicaba que quería continuar la guerra, pero no solo prestando ayuda, sino de forma activa. El primer ministro accedió inmediatamente y puso a su disposición la BBC para que lanzara su mensaje. Ambos convinieron que se realizara después de que el Gobierno francés

196 CHURCHILL, W. S.: La segunda guerra... cit. p. 541.

197 REYNAUD, P.: Memorias de... cit. p. 60. El nuevo Gobierno de Pétain quedaba formado por: «el general Weygand en Defensa Nacional, El general Colson en Guerra, el almirante Darlan en Marina, El general Pujo en Aire, Baudouin Asuntos Exteriores, Pomaret en Interior, Boutheller Hacienda, Rievere en Colonias, Frossard en Obras Publicas, Febvier en Trabajo, Chichery en Agricultura, Ribaud en Educación y lbarnegaray en Pensiones».

198 MONNET, J.: Memorias... cit. p. 30.

199 PÉTAIN, P.: Cuatros años en el poder. Madrid. Prensa Española. 1949, p. 28. Según Pétain: «el armisticio salvó a Francia y contribuyó a la victoria de los Aliados, porque aseguró la libertad del Mediterráneo y la integridad del Imperio». 
solicitara el armisticio 200 .

Con todo ello, el día 18 de junio a las 18 horas, el general De Gaulle se colocaba delante de los micrófonos de la BBC con el texto en el que hacia el Ilamamiento a la Resistencia de la Francia libre. En el llamamiento recordaba que «¡Francia no está sola!»201, y que, uniendo el Imperio francés todavía intacto, unida a Inglaterra podían continuar la guerra utilizando los recursos casi ilimitados de la industria estadounidense hasta conseguir la victoria. No tenían que limitarse a batalla en territorio continental, esa era la misma idea que se había planteado con el proyecto de Unión y que también era la que tenía el propio P. Reynaud con el traslado a África para continuar desde allí la guerra.

\section{LA UNIÓN. REFLEXIÓN FINAL}

Con la llegada de la primavera en 1940, se empezaría a demostrar que la cooperación entre Gran Bretaña y Francia, tenía serias limitaciones que resultaban vitales. La alianza entre Inglaterra y Francia parecía estar a punto de romperse. Los Aliados luchaban contra Alemania cooperando entre ellos, pero por separado, las Fuerzas Aéreas francesas luchaban en inferioridad contra las alemanas. Por ese motivo, a primeros de junio, Jean Monnet le propuso a Churchill unificar ambas Fuerzas Aéreas, lo que corregiría la inferioridad, pero la propuesta no llegó a ser escuchada por el primer ministro británico.

En ese momento la coalición estaba a punto de romperse, mientras Francia se debatía entre la retirada a África o solicitar el armisticio. Gran Bretaña ya pensaba que tendría que continuar la guerra sola, centrándose en la defensa de la isla. J. Monnet se daba cuenta de que la cooperación entre ambos países se había

200 GAULLE, Ch. de.: Memorias de... cit. pp. 69-70.

201 MONNET, J.: Memorias... cit. p. 32. 
chocado contra los límites de la misma y no estaba funcionado, la pésima moral entre las filas francesas y una coalición carente de alma, sin un objetivo común, excepto el de luchar contra la invasión alemana, era insuficiente.

En las primeras semanas de junio de 1940, J. Monnet había estado trabajando en el informe «Anglo-French Unity». En él analizaba todos los escenarios posibles para conseguir la victoria y en todos ellos llegaba a la misma conclusión, si querían lograrla, necesitaban que Inglaterra y Francia unieran sus destinos mediante la unión total de ambas naciones. Sin embargo, J. Monnet quería que la propuesta de unión durase en el tiempo y en vez de plantearla desde un punto de vista militar, la planteó uniendo el destino de ambos países. Los dos pueblos necesitaban actuar como un único pueblo, de modo que los intereses de uno fueran los intereses del otro.

El problema era que las dos naciones actuaban cada una por su lado, por ejemplo, cuando los británicos usaban su Fuerza Aérea tenía que partir desde Gran Bretaña y no usaban las bases francesas, lo que evitaba que lucharan en conjunción con las francesas. Los dos países estaban separando sus destinos y era imprescindible que se volvieran a unir. La propuesta de Unión Franco-Británica era la mejor garantía para que Francia siguiera en la lucha y los destinos de ambas naciones volvieran a unirse. El Gabinete británico acogió la propuesta con gran entusiasmo, realizando el mayor acto de solidaridad de la historia en el que se uniría con Francia en una posición de igualdad. La propuesta de Unión no ocupaba más de una hoja, pero era sin duda el proyecto político más potente de la historia de la integración europea.

El proyecto, como decía P. Reynaud, suponía la independencia de Francia frente a la capitulación que suponía la esclavitud de toda la nación. Sin embargo, el proyecto no llegó a ser ni votado en el Consejo, tras un largo debate, los partidarios del armisticio con el mariscal Pétain a la cabeza, consiguieron que se realizara una votación para solicitar las condiciones del armisticio a Alemania. La propuesta no fue bien entendida por parte de los ministros que esperaban una contestación 
afirmativa de Gran Bretaña a su solicitud de pedir el armisticio a Alemania. Algunos pensaron que el proyecto de Unión se trataba de un plan de última hora y otros que la propuesta no era en un plano de igualdad. El resultado final llevó a Francia a solicitar las condiciones del armisticio al día siguiente y el proyecto de Unión FrancoBritánica, que no llegó a votarse en el Consejo de ministros francés, quedó descartado. Francia había dejado escapar una oportunidad que hubiera cambiado la historia de Europa en el siglo XX.

Lo vivido durante la primavera de 1940, demostró que los límites de la cooperación dan lugar a discusiones, pero que en los momentos claves no sirven para tomar decisiones. Las dudas generadas entre ambas naciones, provocaban que las decisiones vitales que debían tomarse de forma inmediata se retrasaran o no se llegaran a concluir, dándole una ventaja mortal al enemigo. Los límites de la cooperación implican que en aquellas situaciones donde es necesario compartir un destino común, esta se muestra insuficiente, siendo la unión de las naciones implicadas la única solución posible.

\section{BIBLIOGRAFÍA}

BOSCO, A.: Democracy, Federalism, the European Revolution, and Global Governance. Newcastle. Cambridge Scholars Publishing. 2020, p. 164

BOSCO, A.: June 1940, Great Britain and the First Attempt to Build a European Union. Newcastle. Cambridge Scholars Publishing. 2016, p. 2

CHURCHILL, W. S.: La segunda guerra mundial. Devoto, A. (trad.). Madrid. La esfera de los Libros. 2004, p. 257

DUCHÊNE, F.: Jean Monnet. The first statesman of interdependence. New York/London. W. W. Norton \& Company. 1994, p. 77

GAULLE, CH. de.: Memorias de guerra. Madrid. La esfera de los Libros. 2005, p. 64.

Ihering. Cuadernos de Ciencias Jurídicas y Sociales N ․ㅡ 4 (2021)

DOI: https://doi.org/10.51743/ihering.275 
KERSHAW, I.: Hitler. 1936-1945. Barcelona. Ediciones península. 2000, pp. 245-246.

LIPGENS, W. (Ed.): Documents on the History of European Integration 2. Plans for European Union in Great Britain and in Exile 1939-1945. Berlin/New York. Walter de Gruyter. 1986, pp. 57-58

MACMILLAN, H.: The Blast of War. 1939-1945. London/Melbourne/Toronto. New York, Harper \& Row. 1967, p. 11.

MONNET, J.: Memorias. Martínez García, J. (trad.). Madrid. Instituto Universitario de Estudios Europeos y Ediciones Encuentro. 2010, p. 73

PÉREZ-BUSTAMANTE, R.: Historia política de la Unión Europea 1940-1945. Madrid. Dykinson 1995, p. 40

PÉTAIN, P.: Cuatros años en el poder. Madrid. Prensa Española. 1949, p. 28.

PHILIP, O.: Le probleme de I'Union Européenne. Neuchâtel. Baconnière. 1950, pp. 167-168.

REYNAUD, P.: Memorias de... sobre la catástrofe de Francia. Madrid. Edica. 1945 , p. 33

SAN MIGUEL PÉREZ, E.: La civilización de los inconformistas: el ideal europeo en el pensamiento político y la acción institucional (1919-1949). Madrid. Fundación Universitaria Española. 2005, p. 107

SELF, R. C.: Neville Chamberlain: A Biography. London. Ashate Publishing Limited. 2006, p. 6

STREIT, C. K.: Union Now. A Proposal for a Federal Union of the Democracies of the North Atlantic. New York/London. Harper \& Brothers Publishers. 1939, p. 12. 
